\title{
A new genus of parasitic copepod (Siphonostomatoida: Caligidae) from the razorback scabbardfish, Assurger anzac (Trichiuridae) off New Caledonia
}

\author{
Geoffrey A. Boxshall ${ }^{1}$ and Jean-Lou Justine ${ }^{2}$ \\ ${ }^{1}$ Department of Zoology, The Natural History Museum, Cromwell Road, London SW7 5BD, UK; \\ ${ }^{2}$ Équipe Biogéographie Marine Tropicale, Unité Systématique, Adaptation, Évolution (CNRS, UPMC, MNHN, IRD), Institut de \\ Recherche pour le Développement, BP A5, 98848 Nouméa Cedex, Nouvelle Calédonie
}

Key words: taxonomy, phylogeny, parasitic copepod, fish host, Caligidae

\begin{abstract}
A new genus and species, Avitocaligus assurgericola gen. et sp. n., of the family Caligidae is established based on an ovigerous female collected from a razorback scabbardfish, Assurger anzac (Alexander), caught off New Caledonia. This is the first record of any parasitic copepod from this fish. The new genus is placed in the Caligidae since it possesses the caligid cephalothorax incorporating the first to third pedigerous somites. It also exhibits biramous first and fourth swimming legs but lacks dorsal plates on the fourth pedigerous somite. This combination of characters serves to differentiate the new genus from existing genera. In addition, it possesses loosely coiled, uniseriate egg sacs, concealed between the middle lamellar plates on the genital complex and the ventral plates on the abdomen. Preliminary phylogenetic analysis with a restricted matrix suggests that the new genus represents the earliest offshoot from the main caligid lineage since it does not exhibit the dominant exopod on the fourth swimming leg found in all other members of the Caligidae, including the genus Euryphorus. It strongly supports the newly recognized monophyletic status of the Caligidae, incorporating the genera formerly placed in the Euryphoridae.
\end{abstract}

The razorback scabbardfish, Assurger anzac (Alexander), is a member of the family Trichiuridae, the cutlassfishes. It is a benthopelagic fish, with a wide distribution through the tropical Atlantic, Indian and Pacific Oceans (Froese and Pauly 2004), but it typically occurs at depths between 150 and $400 \mathrm{~m}$ and is only occasionally caught. It has never been reported as a host of any parasitic copepods. A single scabbardfish caught off the east coast of New Caledonia in April 2003 carried a large ovigerous parasitic copepod belonging to the family Caligidae Burmeister, 1835, which could not be placed in any existing genus.

The family Caligidae currently comprises well over 400 described species in 32 genera. This total includes the five genera formerly attributed to the family Euryphoridae Wilson, 1905 by Kabata (1979) since these two families were formally synonymised by Boxshall and Halsey (2004), in part following the unpublished work of Dojiri (1983). The five euryphorid genera accepted by Kabata (1979) were Euryphorus Milne Edwards, 1840, Gloiopotes Steenstrup et Lütken, 1861, Tuxophorus Wilson, 1908, Alebion Krøyer, 1863 and Paralebion Wilson, 1911 (not Pupulina van Beneden, 1892 as erroneously stated by Boxshall and Halsey 2004, which Kabata 1979 included in the Caligidae). These two families were distinguished primarily on the basis of the presence of dorsal plates on the free fourth pedigerous somite in the euryphorid genera (Kabata 1979). Paralebion was subsequently shown to lack dorsal plates by Prabha (1983). The distribution of other characters, used by earlier authors (e.g. Wilson 1905, 1907), such as the presence or absence of lunules on the frontal plates, the styliform processes on the genital complex, the segmentation of the abdomen and the loss of the endopod of the fourth swimming leg provide little or no support for the separation of the former euryphorid genera from the Caligidae.

The new genus from Assurger anzac might have been classified as a euryphorid, since it possesses biramous first and fourth swimming legs in combination with the caligid cephalothorax incorporating the first to third pedigerous somites, but it lacks dorsal plates on the fourth pedigerous somite. It is described below and the classification of the Caligidae is revisited in the light of the novel data this new parasite provides.

\section{MATERIALS AND METHODS}

Holotype. Ovigerous female from under the operculum of a specimen (Standard Length $=219 \mathrm{~cm}$ ) of Assurger anzac (JNC 407) collected by Geoffrey Bertrand on 5th April 2003, off the east coast of Lifou Island, Loyalty Islands, New Caledonia (20 59'145'S, 16744'795'E). Holotype examined as whole mount and with appendages (except maxillule and legs 5 and 6) dissected from left side of body only. Dissected appendages observed as temporary mounts in lactophenol, on Leitz Diaplan microscope equipped with differential interference optics. Drawings made with the aid of a camera lucida and from photographs. Holotype stored in alcohol and deposited in collections of Muséum national d'Histoire naturelle, Paris, MNHN Cp-2185; parasitological record JNC 407. 
Table 1. Character matrix for preliminary analysis of phylogenetic relationships of the new genus.

\begin{tabular}{|l|l|l|l|l|l|l|l|l|l|}
\hline Genus/Character No. & 1 & 2 & 3 & 4 & 5 & 6 & 7 & 8 & 9 \\
\hline Trebius & 0 & 0 & 0 & 0 & 0 & 0 & 0 & 0 & 0 \\
Avitocaligus & 1 & 0 & 0 & 0 & 0 & 0 & 0 & $?$ & 0 \\
Euryphorus & 1 & 1 & 0 & 0 & 0 & 1 & 0 & 0 & 0 \\
Pupulina & 1 & 1 & 1 & 0 & 0 & 0 & 0 & 1 & 0 \\
Gloiopotes & 1 & 1 & 1 & 1 & 0 & 1 & 0 & 0 & 1 \\
Alebion & 1 & 1 & 1 & 1 & 0 & 1 & 0 & 1 & 1 \\
Tuxophorus & 1 & 1 & 1 & 1 & 1 & 1 & 1 & 0 & 0 \\
Paralebion/Lepeophtheirus & 1 & 1 & 1 & 1 & 1 & 0 & 0 & 0 & 0 \\
Caligus-lineage & 1 & 1 & 1 & 1 & 1 & 0 & 1 & 0 & 0 \\
\hline
\end{tabular}

Scores for Trebius were based on data on Trebius caudatus Krøyer, 1838 taken from Kabata (1979); for Euryphorus, on Euryphorus brachypterus (Gerstaecker, 1853) taken from Kabata (1979); for Pupulina, on Pupulina minor Wilson, 1952 taken from Pillai (1985); for Alebion, on Alebion carchariae Krøyer, 1863 taken from Cressey (1972); for Gloiopotes, on material of Gloiopotes watsoni Kirtisinghe, 1934 (BMNH 1992.93-102); for Tuxophorus, on material of Tuxophorus caligodes Wilson, 1908 (BMNH 1954.9.20.7); for Paralebion, on Paralebion elongatus Wilson, 1911 taken from Pillai (1985) and from unregistered material collected from the carcharhinid Triaenodon obesus (Rüppell, 1837) caught off New Caledonia, and for Caligus, on Caligus curtus Müller, 1785 taken from Kabata (1979). In the analysis Caligus can be considered to represent the other genera of the subfamily Caliginae (with lunules) and Paralebion to represent the subfamily Lepeophtheirinae (remaining genera lacking lunules).

The phylogenetic relationships between basal caligid taxa were analysed using PAUP 4.0b10. Branch and Bound analysis with all characters unordered yielded a single tree with a tree length of 12. The consistency index was 0.73 and the homoplasy index 0.27 . The tree was rooted using Trebius Krøyer as outgroup. The data matrix is presented in Table 1 and the character numbers (and scores in matrix) are as follows:

Character 1. Caligiform cephalothorax not incorporating third pedigerous somite / incorporating third pedigerous somite $(0 / 1)$

Character 2. Leg 4 endopod more than half length of exopod and bearing well-developed plumose setae; exopod with small outer spines/leg 4 with endopod less than half length of exopod, with small setae; exopod with large spines $(0 / 1)$

Character 3. Leg 4 endopod present / absent $(0 / 1)$

Character 4. Leg 4 exopod with inner setae/ leg 4 exopod lacking inner setae $(0 / 1)$

Character 5. Leg 1 with well-developed 2-segmented endopod armed with $0-0 ; 3$ setation / endopod vestigial $(0 / 1)$

Character 6. Fourth pedigerous somite without dorsal plates / with dorsal plates $(0 / 1)$

Character 7. Frontal plates without lunules/with lunules (0/1)

Character 8. Outer exopodal spines on exopod of leg 2 as in female / modified in male / unknown ( $0 / 1 /$ ? $)$

Character 9. Fifth legs normally developed / fifth legs forming stylet-like processes $(0 / 1)$

\section{RESULTS}

\section{Avitocaligus gen. n.}

Diagnosis. Female body dorsoventrally flattened, comprising caligiform cephalothorax, incorporating first to third pedigerous somites, free fourth pedigerous somite, a broad genital complex with 2 pairs of large expanded, lamellar plates (dorsal and middle plates), and a free abdomen of 2 somites, with first abdominal somite bearing paired, lamellar plates ventrally. Genital apertures concealed between middle plates on genital complex and ventral plates on abdomen. Caudal rami with 6 setae. Rostrum absent; paired frontal plates without lunules. Nauplius eye present. Antennule 2segmented; first segment with 27 setae, second with 13 setae. Antenna uniramous, comprising coxa, basis and laterally directed subchela formed by fusion of endopod and distal claw; exopod absent. Postantennal process absent. Oral cone tapering, formed by both labrum and labium. Mandible reduced to stylet bearing 12 teeth on one side near apex. Maxillule bilobed, with basal portion incorporated into body wall; anterior lobe papillate, bearing 3 setae; posterior lobe an unarmed spinous process. Maxilla brachiform, comprising syncoxa (lacertus) and basis (brachium) bearing calamus and canna distally. Maxilliped 2-segmented, comprising massive protopod (corpus) and distal subchela representing fused endopodal segments plus terminal claw. Sternal furca absent. Swimming leg 1 with coxa and basis slightly offset; biramous with exopod and endopod 2-segmented; distal endopod segment armed with 3 plumose setae. Inner seta on basis of leg 1 present. Leg 2 biramous, with protopod comprising coxa and basis; both rami 3-segmented. Leg 3 with coxa and basis fused into flattened sympod; leg pair connected by expanded intercoxal sclerite and forming broad plate sealing rear margin of cephalothorax; both rami 3-segmented. Fourth leg biramous; coxa and basis partly fused, both rami 2-segmented. Intercoxal sclerites present on legs 1 to 4. Spine and seta formula as follows:

\begin{tabular}{l|c|c|c|c} 
& coxa & basis & $\begin{array}{c}\text { exopodal } \\
\text { segments }\end{array}$ & $\begin{array}{c}\text { endopodal } \\
\text { segments }\end{array}$ \\
\hline leg 1 & $0-0$ & $1-1$ & I-0; III,I,3 & $0-0 ; 3$ \\
leg 2 & $0-1$ & $1-0$ & I-1; I-1; III,5 & $0-1 ; 0-2 ; 6$ \\
leg 3 & $0-1$ & $1-0$ & I-1; I-1; III,4 & $0-1 ; 0-2 ; 4$ \\
leg 4 & $0-0$ & $1-0$ & I-0; III,4 & $0-1 ; 3$
\end{tabular}



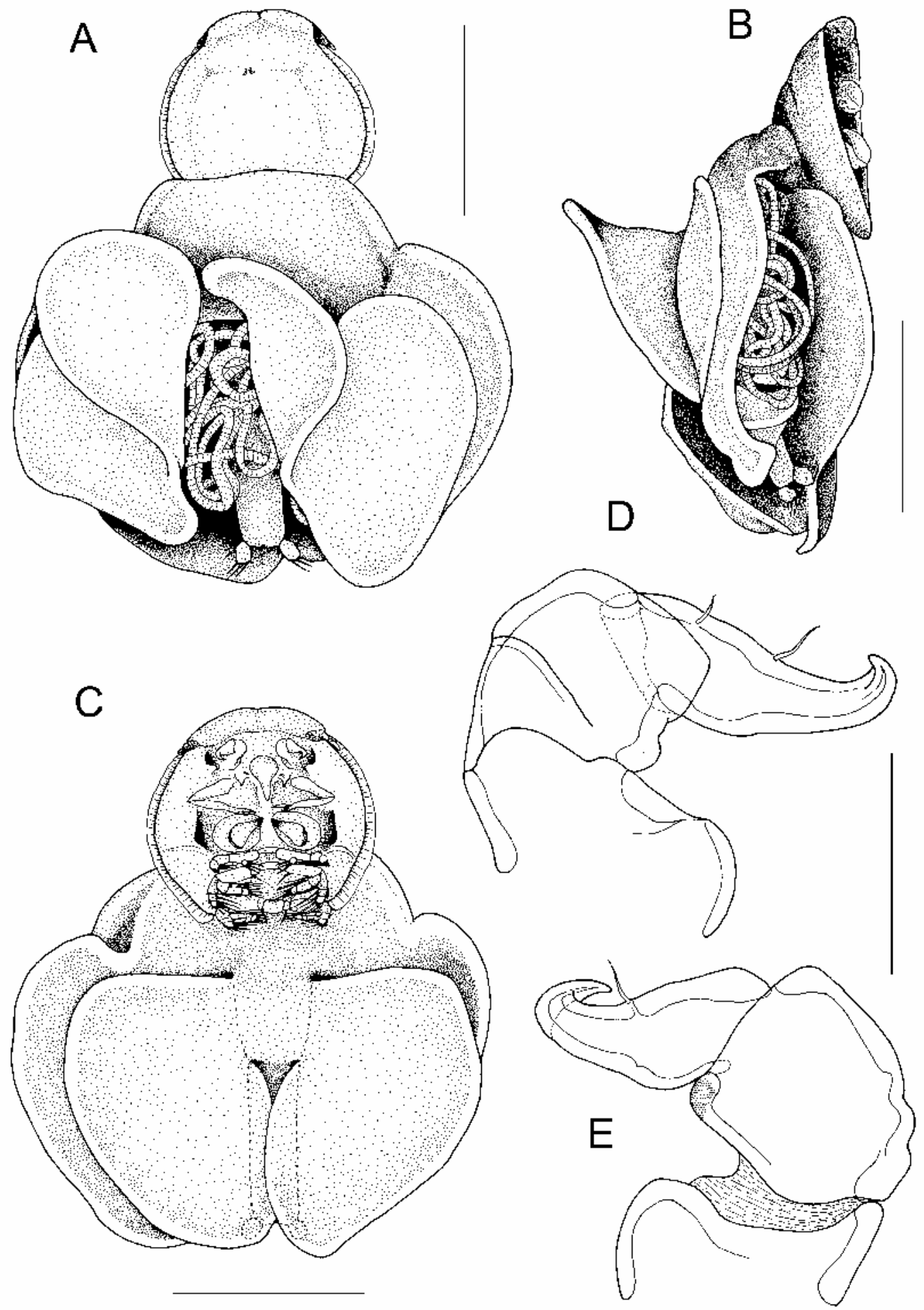

Fig. 1. Avitocaligus assurgericola gen. et sp. n. holotype female. $\mathbf{A}$ - habitus, dorsal; $\mathbf{B}$ - lateral; $\mathbf{C}$ - ventral, with broken lines indicating outlines of abdominal somites; D - antenna, ventral; $\mathbf{E}$ - antenna, dorsal. Scale bars: A-C = $5 \mathrm{~mm} ; \mathrm{D}, \mathrm{E}=0.5 \mathrm{~mm}$. 
Legs 5 and 6 unknown (could not be observed without damage to holotype). Egg sacs uniseriate but loosely coiled within protected space defined by lamellar plates on genital complex.

Male unknown.

Type species: Avitocaligus assurgericola gen. et sp. n., by original designation.

E t y m o 1 o g y: The generic name combines the Latin word avitus meaning "from ancestors" or "ancestral" with the name of the type genus of the family, Caligus. The name refers to the basal position of the genus as the earliest offshoot from the main stem of the family Caligidae.

Remarks. The new genus belongs to the Caligidae since it possesses a shield-shaped cephalothorax incorporating the first to third pedigerous somites. The cephalothorax forms a sucker provided with marginal membrane laterally, closed off anteriorly by the paired frontal plates, and delimited posteriorly by the broad, apron-like third swimming legs. No other siphonostomatoid family has this form of cephalothorax. Biramous fourth legs are found in only one other genus within the Caligidae, Euryphorus, and both these genera also possess paired lateral lamellar expansions on the abdomen. The new genus can be distinguished from Euryphorus by the following combination of characters: 1) sternal furca absent (present in Euryphorus), 2) leg 4 with plumose setae on endopod and reduced outer margin spines on exopod (endopod with short naked setae, and exopod with robust outer spines), 3) egg sacs loosely coiled (egg sacs linear), 4) fourth pedigerous somite small, without lamellae (dorsal lamellae present on fourth pedigerous somite), and 5) paired dorsal and middle lamellar expansions present on genital complex (small posterior expansions only).

The new genus resembles Parapetalus Steenstrup et Lütken, 1861 in the presence of lateral expansions on the genital complex. However, Parapetalus species also possess paired expansions along the lateral margins of the free abdominal somites, which are lacking in the new genus. In addition, Parapetalus species have uniramous fourth legs and the endopod of leg 1 takes the form of a tiny, unsegmented vestige.

\section{Description}

\section{Avitocaligus assurgericola gen. et sp. n.}

Female body (Fig. 1A-C) dorsoventrally flattened; body length $14.5 \mathrm{~mm}$ measured from anterior margin of frontal plates to posterior margin of caudal rami, excluding caudal setae; maximum width $13.1 \mathrm{~mm}$, measured at widest point of lamellar plates on genital complex. Cephalothorax caligiform, incorporating first to third pedigerous somites. Dorsal cephalothoracic shield provided with conspicuous marginal membrane laterally; frontal plates thick, lacking marginal membrane; lunules absent. Nauplius eye visible dorsally through cuticle (Fig. 1A). Fourth pedigerous somite very short, forming 'waist' between cephalothorax and genital complex, lacking dorsal lamellae. Genital complex markedly broader than cephalothorax; provided with 2 pairs of large expanded, lamellar plates. Middle plates originating anterior to dorsal plates, extending along margin of genital complex, then produced posteriorly into free plate. Dorsal plates originating along posterior margin of genital complex, mostly free and folded into horizontal section extending posteriorly, in a parallel plane to the ventral plates, and erect, almost vertical section nearly meeting at dorsal midline. Abdomen comprising 2 somites: first somite short, bearing paired ventral lamellar plates (Fig. 1C), arising along ventrolateral margin and extending posteriorly, overlapping slightly at ventral midline (Fig. 1C); second abdominal somite, elongate, concealed ventrally by abdominal plates. Caudal rami dorsoventrally flattened, armed with 6 plumose setae (Fig. 4A). Middle genital plates and abdominal (ventral) plates concealing genital apertures, creating protected space within which uniseriate egg sacs loosely coiled (Fig. 1A, B).

Antennule 2-segmented (Fig. 2A); first segment with total of 27 irregularly plumose setae, arranged in row of 17 larger anteroventral margin setae, row of 8 smaller setae on ventral surface, close to anterior margin and 2 dorsal setae: second segment slender, with 1 posterior seta located in middle of margin plus apical array of 12 setal elements (no aesthetasc identifiable).

Antenna uniramous (Fig. 1D, E), comprising coxa, basis and curved, laterally directed subchela formed by fusion of endopod and distal claw. Coxa unarmed. Basis unarmed but with patch of striated cuticle dorsally at distal corner. Subchela forming strong claw, with sclerotized tip; bearing 2 slender setae proximally near anterior margin. Postantennal process absent, but raised knob-like area on ventral cephalothoracic surface posterolateral to tip of claw (Fig. 1C).

Oral cone tapering distally with narrow opening. Mandible elongate, stylet-like (Fig. 2C) bearing 12 teeth on one side near apex (Fig. 2D).

Maxillule with basal portion incorporated into ventral cephalothoracic wall; anterior papilla bearing 3 setae; posterior lobe a tapering spiniform process.

Maxilla (Fig. 2E) well developed, brachiform, comprising unarmed syncoxa (lacertus) and basis (brachium) bearing calamus and canna at apex plus flabellum just distal to midlength on anterior margin. Calamus about 1.5 times longer than canna. Flabellum short, comprising deeply serrated membrane. Maxilla with conspicuous, reinforced duct at base.

Maxilliped comprising massive corpus (Fig. 2B) and distal subchela representing fused endopodal segments plus heavily sclerotized terminal claw. Corpus unarmed but with slight swelling in myxal area, opposing tip of claw. Subchela subdivided by incomplete suture line, and bearing single seta about at level of suture.

Sternal furca absent. 


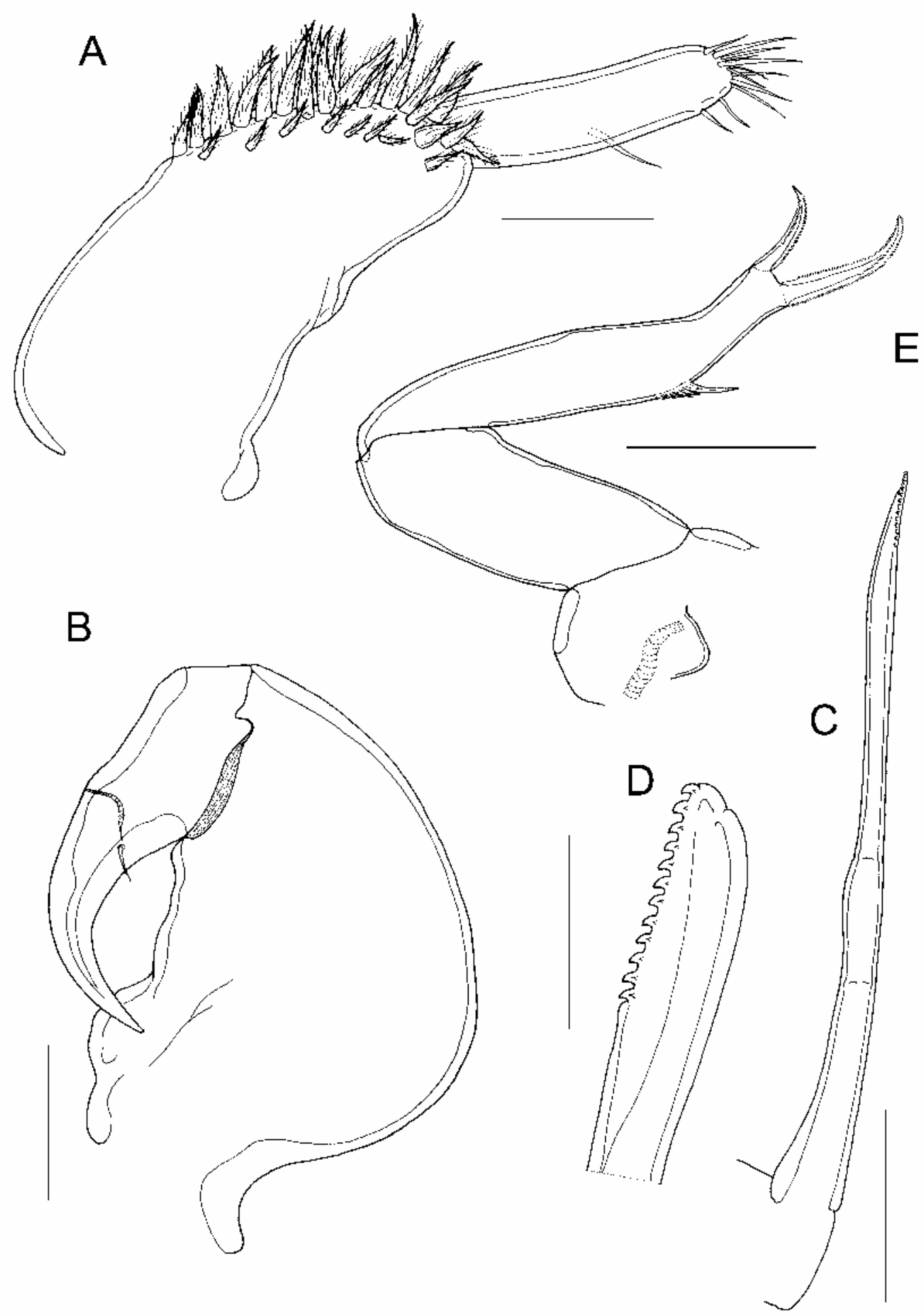

Fig. 2. Avitocaligus assurgericola gen. et sp. n. holotype female. A - antennule, ventral; $\mathbf{B}$ - maxilliped, posterior; $\mathbf{C}$ - mandible; $\mathbf{D}$ - teeth at tip of mandible; $\mathbf{E}$ - maxilla, ventral. Scale bars: $\mathrm{A}=200 \mu \mathrm{m} ; \mathrm{B}, \mathrm{E}=0.5 \mathrm{~mm} ; \mathrm{C}=250 \mu \mathrm{m} ; \mathrm{D}=125 \mu \mathrm{m}$. 
Leg 1 biramous (Fig. 3A): with protopod comprising coxa and basis; coxa unarmed. Basis rectangular with outer seta and inner basal seta located near to origin of endopod. Exopod 2-segmented; large robust first segment carrying outer distal spine, lacking inner seta but with inner marginal row of fine pinnules; second segment with 3 distal margin spines, outermost simple, second and third with bifid tips (Fig. 3B), small inner distal angle seta, and 3 long plumose setae on inner margin. Endopod 2-segmented (Fig. 3A); first segment unarmed; second segment armed with 3 plumose setae around inner margin; outer margin with row of fine pinnules.

Leg 2 biramous (Fig. 3C); protopod comprising coxa and basis; coxa short, bearing plumose inner seta and surface sensilla; basis elongate, armed with short outer distal spine, single sensilla on ventral surface near margin, and provided with extensive flap of marginal membrane along inner (posterior in life as leg directed laterally) margin and another reflexed flap of membrane dorsally, along outer margin and extending well onto first exopodal segment (dotted in Fig. 3C). Both rami 3segmented. Exopod with outer spines unipectinate (Fig. 3D) and inner setae plumose; proximal seta on inner margin of third segment shorter than setae on either side; first segment with row of pinnules along inner margin. Endopod directed medially; first segment with strongly convex, thickened lateral margin ornamented with row of fine pinnules; second segment elongate, with thickened lateral margin lacking row of fine pinnules; all setae plumose.

Leg 3 pair fused with expanded, flattened intercoxal sclerite, to form broad transverse plate (Fig. 4B, C). Intercoxal sclerite with extensive flap of membrane along posterior margin. Coxa and basis incompletely fused, with partial suture line on ventral surface marking plane of fusion (Fig. 4C). Coxa with outer part thick, housing extensive musculature - not flat and planar; armed with large inner plumose seta. Basis with tiny outer seta carried on small protrusion on dorsal surface of limb; posterior margin with flap of membrane and with 2 sensillae near margin. Both rami 3-segmented. Exopod with stout, naked outer spines, distal spine bipinnate, inner setae plumose. Endopod directed medially, with posterior margins of first and second segments ornamented with double rows of fine pinnules: all endopodal setae plumose.

Fourth leg biramous (Fig. 3E); coxa and basis partly fused, separated by incomplete suture line on dorsal surface. Coxa unarmed. Basis with small plumose seta laterally and single sensilla near posterior margin. Both rami 2-segmented. First exopodal segment with outer spine and short section of membrane on inner margin. Distal exopodal segment compound, representing second and third segments, bearing total of 4 unipectinate outer spines (Fig. 4D), distalmost longest, plus 3 short, bilaterally pinnate setae. First and second endopodal segments each with row of pinnules along outer margin; all setae well developed and plumose.

Legs 5 and 6 not observed (genital region concealed beneath lamellar plates which were not removed in unique specimen).

T y $\mathrm{p}$ e $\mathrm{h}$ o s t: Assurger anzac (Alexander, 1917) (Trichiuridae, Perciformes).

Site of infection: Gills.

Type 1 o c a lity: Off the east coast of Lifou Island, Loyalty Islands, New Caledonia (20 59'145's, $\left.167^{\circ} 44^{\prime} 795^{\prime \prime} \mathrm{E}\right)$.

Prevalence and intensity: 100\%(1 female from 1 host).

E t y $\mathrm{m} \mathrm{ol}$ o $\mathrm{g}$ y: The species name is based on the name of the host genus, Assurger.

D e p os ition of ty pes: Holotype stored in alcohol and deposited in collections of Muséum national d'Histoire naturelle, Paris, MNHN Cp-2185.

\section{DISCUSSION}

The great majority of caligids have a biramous first leg but in most the endopod is a vestigial lobate process and the limb appears to be functionally uniramous. A well-developed, 2-segmented endopod with the setal formula $0-0,3$ is retained in four genera, Alebion, Euryphorus, Pupulina and Avitocaligus. In Gloiopotes the endopod is also 2-segmented and the distal segment carries 3 setae but the entire ramus is tiny and the setae are minute. In all other caligids, including Tuxophorus and Paralebion, the endopod is further reduced. The 2segmented endopod with $0-0,3$ setation pattern is also shared with the families Cecropidae, Dissonidae, Pandaridae and Trebiidae, and probably represents the groundplan condition for this entire lineage of caligiform families. This form of endopod is synapomorphic for this lineage with respect to the Pennellidae and the dichelesthiiform families, such as the Eudactylinidae, Hatschekiidae and Kroyeriidae, at least some members of which express three endopodal segments, armed with inner setae on proximal segments, and more than three setae on the apical segment.

Most caligids have a uniramous fourth leg, lacking an endopod, but with a well-developed exopod armed with strong outer margin spines. In some genera, such as Alebion, the fourth leg is further reduced (Cressey 1972). A biramous fourth leg, with an endopod, is retained only in Avitocaligus and Euryphorus but the form of the limb differs markedly between these two genera. Euryphorus brachypterus (Gerstaecker, 1853) females have a well-developed 3-segmented exopod armed with strong outer and distal margin spines and retaining vestiges of inner margin setae on the second and third segments (Kabata 1979). The endopod is small, only half the length of the exopod, and is indistinctly 3-segmented. It carries five small inner setae, one on the first segment, one marking the non-functional articulation between the second and third segments, and three on 
Boxshall, Justine: New genus of Caligidae

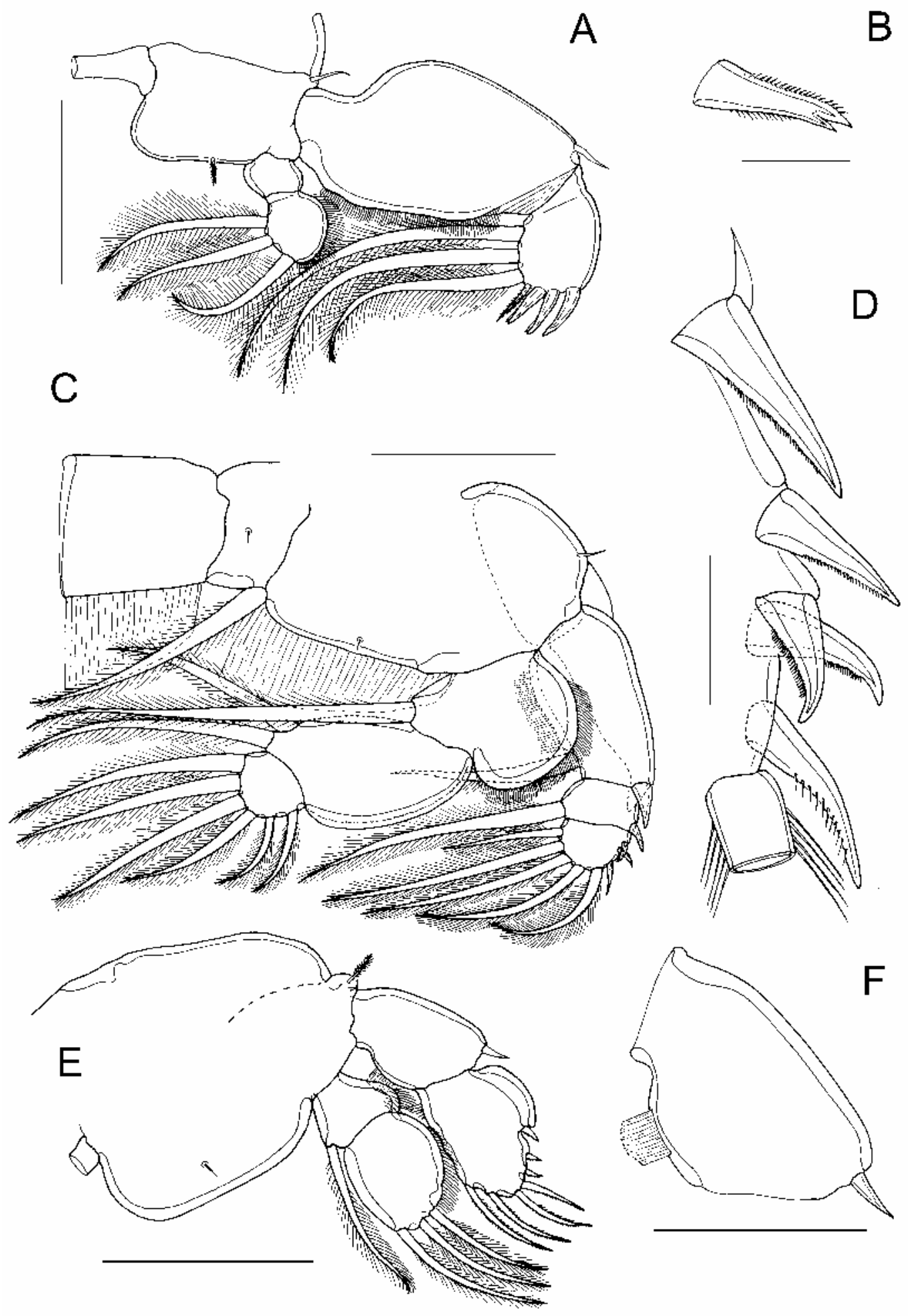

Fig. 3. Avitocaligus assurgericola gen. et sp. n. holotype female. A - leg 1 ventral; $\mathbf{B}$ - detail of second distal spine on apex of exopod; C - leg 2, ventral; D - detail of exopodal spines; $\mathbf{E}$ - leg 4, ventral; F - detail of first exopodal segment showing membrane on inner margin. Scale bars: A, C, E $=0.5 \mathrm{~mm} ; \mathrm{B}, \mathrm{D}=100 \mu \mathrm{m} ; \mathrm{F}=250 \mu \mathrm{m}$. 


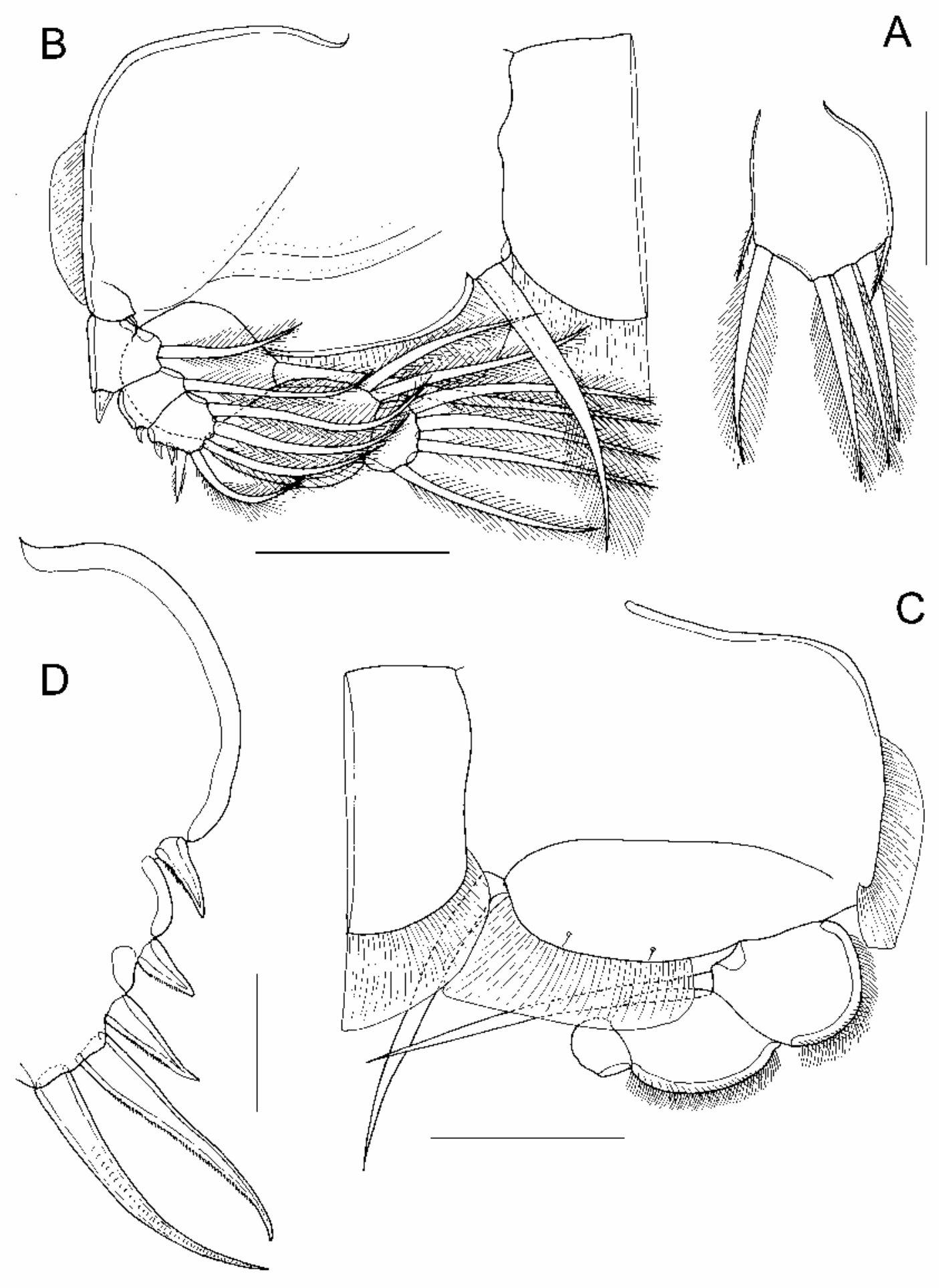

Fig. 4. Avitocaligus assurgericola gen. et sp. n. holotype female. A - left caudal ramus, dorsal; $\mathbf{B}-\operatorname{leg} 3$, ventral; $\mathbf{C}-\operatorname{leg} 3$, dorsal view with exopod and most of endopodal setae omitted; D - leg 4, detail of outer margin of distal exopodal segment. Scale bars: $\mathrm{A}-\mathrm{C}=0.5 \mathrm{~mm} ; \mathrm{D}=100 \mu \mathrm{m}$. 


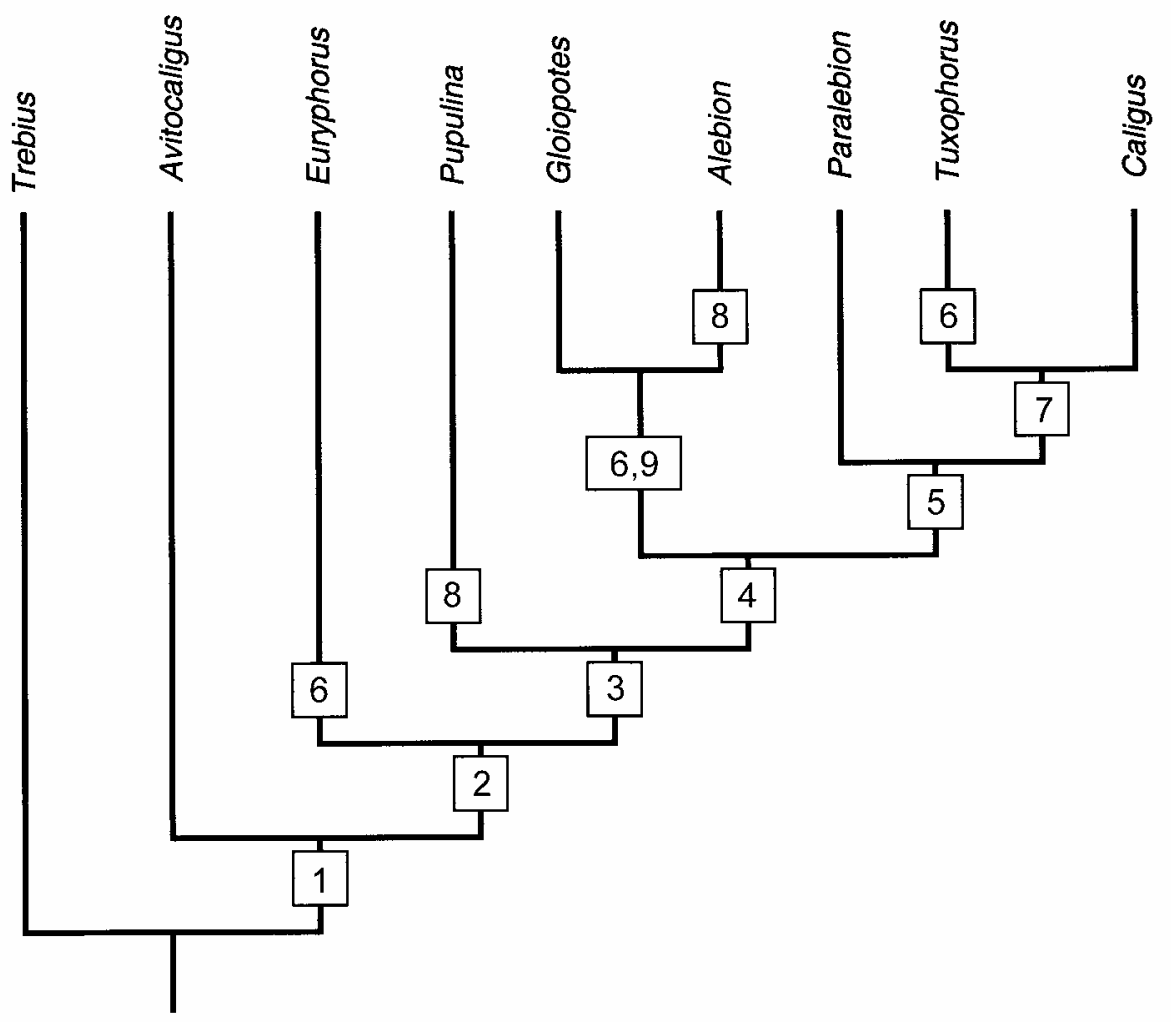

Fig. 5. Tree generated by preliminary analysis of basal genera in Caligidae using matrix in Table 1. Numbers in boxes on tree are character numbers and show position of change(s) from plesiomorphic to apomorphic state. Paralebion represents the Lepeophtheirinae clade (lacking lunules) and Caligus represents the Caliginae lineage (with lunules).

the distal margin. The form of this leg already displays key attributes of the typical caligid leg: the coxa and basis are fused to form an elongate, compound protopodal segment, the exopod is the dominant ramus, and the outer margin exopodal spines are strongly developed. In contrast, Avitocaligus does not display these typical caligid attributes: the rami are of similar size, the coxa and basis are partly separated and do not form an elongate protopod, and the outer exopodal spines are more weakly developed than the inner setae. Avitocaligus, Euryphorus and Pupulina all possess inner setae on the second and third exopodal segments of leg 4 but these are lost in all other genera of caligids, which have only outer margin spines on this ramus.

Four genera, Alebion, Euryphorus, Gloiopotes, and Tuxophorus, possess dorsal lamellar expansions on the fourth pedigerous somite. These are absent from all other caligids, including Avitocaligus and Pupulina.

The presence of lunules on the frontal plates of the cephalothorax has been used a key synapomorphy of the 16 genera comprising the subfamily Caliginae. Lunules are also present in Tuxophorus which was previously treated as a euryphorid.

Avitocaligus is unique within the Caligidae in the possession of loosely coiled egg sacs. All other caligids possess straight uniseriate egg sacs that trail behind the body. However, in several other families of fish- parasitic siphonostomatoids, including the Cecropidae, Pandaridae and Pennellidae, both linear and coiled egg sacs are present. The form of the uniseriate egg sacs has been used as a generic level discriminant in all three of these families (Kabata 1972, 1979, Boxshall 1986).

A full phylogenetic analysis of the entire family is not possible at present since the male of Avitocaligus is unknown and too many other genera are insufficiently well characterized, but preliminary analysis allows us to generate a rough estimate of relationships between the basal taxa within the Caligidae (Fig. 5). This scheme identifies Avitocaligus as the first offshoot of the Caligidae, separated from the main lineage by the lack of dominance of the fourth leg exopod. The next genus to branch off is Euryphorus, which retains the fourth leg endopod (lost in the main lineage). Then Pupulina is separated on the basis of its retention of inner setae on the exopodal segments of fourth leg (these are lost on the main lineage). The following dichotomy separates Gloiopotes-Alebion, characterized by the presence of dorsal plates on the fourth pedigerous somite and the stylet-like fifth leg, from Paralebion-TuxophorusCaligus, characterized by the reduction of the first leg endopod to a vestigial lobe. The latter lineage divides into the subfamily Caliginae, represented by Tuxophorus-Caligus and characterized by the presence of lunules, and Paralebion. 
The analysis used unordered character states but no characters exhibited any reversals. Only two characters exhibited homoplasy: character 6 (the presence of dorsal plates on the fourth pedigerous somite) and character 8 (the presence of sexually dimorphic spines on the exopod of leg 2). The former arose three times, in Euryphorus, in the Gloiopotes-Alebion lineage and in Tuxophorus. The latter arose twice, in Alebion and in $\mathrm{Pu}$ - pulina. The results of this analysis, though preliminary, are fully in accord with the decision to synonymise the families Caligidae and Euryphoridae (Boxshall and Halsey 2004).

Acknowledgement. We are grateful to Geoffrey Bertrand, observer for the Comminauté du Pacifique - Secrétariat, Nouméa, New Caledonia, who collected the specimen.

\section{REFERENCES}

BOXSHALL G.A. 1986: A new genus and two new species of Pennellidae (Copepoda: Siphonostomatoida) and an analysis of evolution within the family. Syst. Parasitol. 8: 215225

BOXSHALL G.A., HALSEY S.H. 2004: An Introduction to Copepod Diversity. The Ray Society, London, 966 pp.

CRESSEY R.F. 1972: Revision of the genus Alebion (Copepoda: Caligoida). Smithson. Contrib. Zool. 123: 1-29, figs. $1-132$

DOJIRI M. 1983: Revision of the genera of the Caligidae (Siphonostomatoida), copepods predominantly parasitic on marine fishes. Unpublished $\mathrm{PhD}$ thesis, Boston University, $721 \mathrm{pp}$.

FROESE R., PAULY D. (Eds.) 2004: FishBase. World Wide Web electronic publication. www.fishbase.org [24 September 2004].

KABATA Z. 1972: Copepoda parasitic on Australian fishes. XI. Impexus hamondi new genus, new species with a key to the genera of Lernaeoceridae. Proc. Biol. Soc. Wash. 85 (27): 317-322.

KABATA Z. 1979: Parasitic Copepoda of British Fishes. The Ray Society, London, 468 pp.

PILLAI N.K. 1985: Fauna of India. Parasitic Copepods of Marine Fishes. Zoological Survey of India, Calcutta, 900 pp.

PRABHA C. 1983: A discussion on the genera of Caligidae (Copepoda). In: P.A. John (Ed.), Selected Papers on Crustacea. Prof. (Dr) N. Krishna Pillai felicitation volume. Prof. N. Krishna Pillai Farewell Committee, Trivandrum, pp. 49-68.

WILSON C.B. 1905: North American parasitic copepods belonging to the family Caligidae. Part 1 . The Caliginae. Proc. U.S. Natl. Mus. 28 (1404): 479-672, pls. 5-29.

WILSON C.B. 1907: North American parasitic copepods belonging to the family Caligidae. Part 2. The Trebinae and Euryphorinae. Proc. U.S. Natl. Mus. 31 (1504): 669-720, pls. 15-20. 